\title{
Analysis of linoleoyl and oleoyl macrogolglycerides by high performance liquid chromatography coupled to the atmospheric pressure photoionization mass spectrometry
}

\author{
Kamilia Kemel $^{1, *}$, Danielle Libong ${ }^{1}$, Audrey Solgadi ${ }^{2}$, Sana Tfaili ${ }^{1}$, Arlette Baillet-Guffroy ${ }^{1}$ and Cécile Laugel ${ }^{1}$ \\ ${ }^{1}$ U-Psud, Univ. Paris-Saclay, Lip(Sys) Chimie Analytique Pharmaceutique, EA7357, UFR-Pharmacy, Châtenay-Malabry, France \\ 2 SAMM, UMS IPSIT, Université Paris Sud, Université Paris-Saclay, Chatenay-Malabry, France
}

Received 28 November 2019 - Accepted 2 April 2020

\begin{abstract}
Linoleoyl macrogolglyceride (LM) and oleoyl macrogolglyceride (OM) are pharmaceutical ingredients, obtained from corn and apricot kernel oils respectively. This study aims to know the detailed chemical composition of LM and OM, in order to understand their roles in pharmaceutical formulations. These two products were analyzed by non-aqueous reversed phase high-performance liquid chromatography (NARP-HPLC), using Vintage Series KR C18 column $(250 \times 4.6 \mathrm{~mm}, 5 \mu \mathrm{m})$ and non-aqueous acetonitrile/ acetone mixture as mobile phase. The ionization source used was atmospheric pressure photoionization (APPI) and the analyzer was LTQ-Orbitrap (hybrid analyzer: double linear ion trap coupled to a Fourier transform orbital trap). LM and OM consist of complex mixtures, constituted of mono-(MG), di-(DG) and triglycerides (TG) and mono-(MPEGE) and di PEG-6 esters (DPEGE) of linoleic acid (18:2) for LM and of oleic acid (18:1) for OM. NARP-HPLC-APPI method allowed the separation and the identification of the glyceride classes (MGs, DGs and TGs) and the PEG esters of different chain lengths (PEG-chain lengths of fatty acid moieties and number of units of ethylene oxide), at the same time and in one single run, for both products LM and OM. The comparative study between LM and OM showed that, a higher presence of linoleic esters for LM, and a higher presence of oleic esters for OM.
\end{abstract}

Keywords: monoglycerides / diglycerides / triglycerides / PEG-6 esters / reverse phase high-performance liquid chromatography / atmospheric pressure photoionization

Résumé - Analyse des macrogolglycérides de linoléoyle et d'oléoyle par chromatographie liquide à haute performance couplée à la spectrométrie de masse par photoionisation à pression atmosphérique. Les macrogolglycérides de linoléoyle (LM) et oléoyle (OM) sont des ingrédients pharmaceutiques, obtenus respectivement à partir d'huiles de maïs et de noyaux d'abricot. Cette étude vise à connaître la composition chimique détaillée des LM et OM, afin de comprendre leur rôle dans les formulations pharmaceutiques. Ces deux produits ont été analysés par chromatographie liquide haute performance en phase inverse non aqueuse (NARP-HPLC), en utilisant une colonne KR C18 de la série Vintage $(250 \times 4,6 \mathrm{~mm}$, $5 \mu \mathrm{m}$ ) et un mélange acétonitrile/acétone non aqueux comme phase mobile. La source d'ionisation utilisée était la photoionisation à la pression atmosphérique (APPI) et l'analyseur était le LTQ-Orbitrap (analyseur hybride : double piège à ions linéaire couplé à un piège à mouvement orbital utilisant la transformée de Fourier). LM et OM sont des mélanges complexes, constitués de mono-(MG), di-(DG) et triglycérides (TG) et de mono(MPEGE) et di esters de PEG-6 (DPEGE) d'acide linoléique (18:2) pour LM et d'acide oléique (18:1) pour OM. La méthode NARP-HPLC-APPI a permis la séparation et l'identification des classes de glycérides (MG, DG et TG) et des esters de PEG de différentes longueurs de chaine (PEG-chaînes d'acide gras et nombre d'unités d'oxyde d'éthylène), simultanément et en un seul passage, pour les deux produits LM et OM. L'étude comparative entre LM et OM a montré qu'il y avait une plus d'esters linoléiques pour LM et plus d'esters oléiques pour OM.

Mots clés : monoglycérides / diglycérides / triglycérides / esters PEG-6 / chromatographie liquide haute performance en phase inverse / photoionisation à pression atmosphérique

*Correspondence: kemelkamilia@icloud.com 

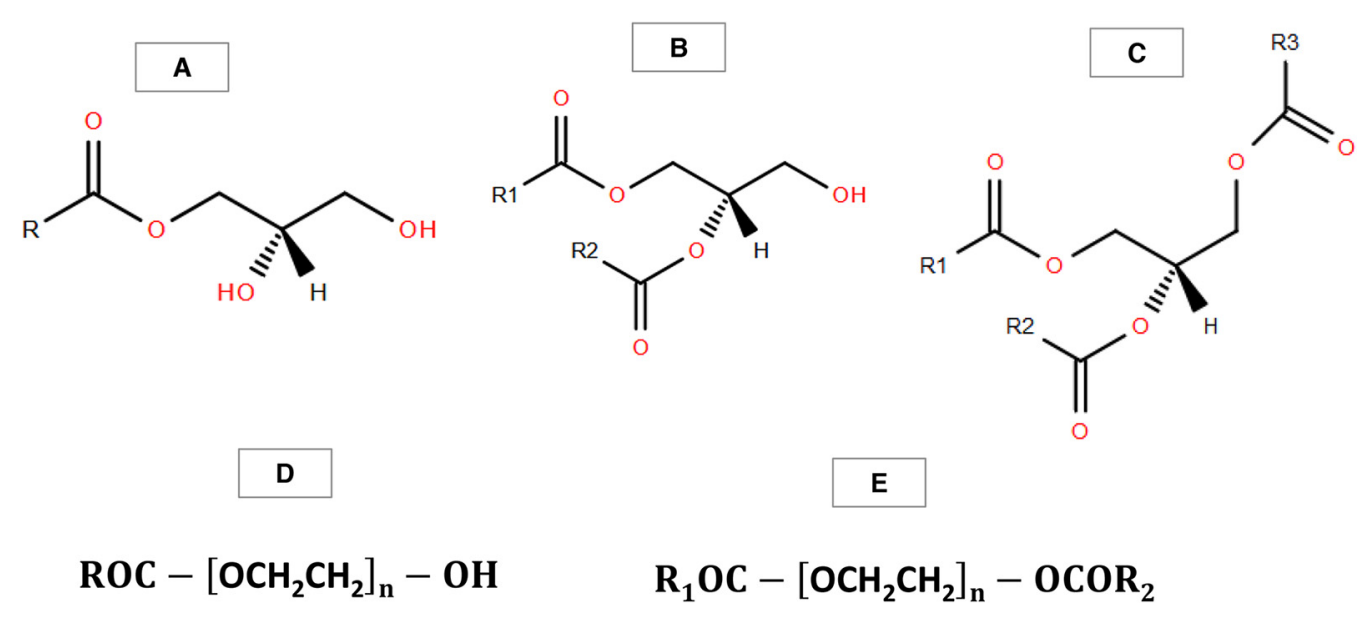

Fig. 1. Chemical structures of MG (A); DG (B); TG (C); MPEGE (D); and DPEGEs (E) (LIPID MAPS, 2003; Abdullah et al., 2017).

\section{Introduction}

Vegetable oils are products used for food and therapeutic purposes. They are used as raw material in the pharmaceutical, cosmetic, detergent industries... as active ingredient or excipient in the crude or transformed state. The transformation of vegetable oils allows to obtain compounds with improved physicochemical and/or organoleptic characteristics for examples: stability during storage, odor, color... (Soumanou et al., 2005).

Linoleoyl macrogolglyceride (LM) and oleoyl macrogolglyceride (OM) are pharmaceutical ingredients with various roles: dissolution enhancers; emulsifying agents; nonionic surfactants; penetration agents; solubilizing agents; sustained release agents. They are recommended for use in pharmaceutical formulations administered by oral, dermal, rectal and vaginal routes. LM is constituted of mono-, di- and triglycerides of linoleic acid (MG (18:2), DG (18:2/18:2) and TG (18:2/18:2/18:2)) and mono- and di-PEG-6 esters of linoleic acid (MPEGE (18:2) and DPEGE (18:2/18:2)) (Labrafil $^{\circledR}$ M $\left.2125 \mathrm{CS}\right)$. OM is constituted of mono-, diand triglycerides of oleic acid (MG (18:1), DG (18:1/18:1) and TG (18:1/18:1/18:1)) and mono- and di-PEG-6 esters of oleic acid (MPEGE (18:1) and DPEGE (18:1/18:1)) $\left(\right.$ Labrafil $^{\circledR} \mathrm{M}$ 1944 CS) (Fig. 1).

These two ingredients could exhibit some differences of behavior during the manufacturing of complex pharmaceutical formulations such as nanocarriers. One hypothesis is that the physical stability of these formulations could be affected by prevailing fine chemical composition of these two ingredients.

The purpose of this paper was to develop a separative analytical method using an optimized gradient of elution that will allow the separation of each compound within glycerides subclasses and PEG-esters of LM and OM, to be able to establish a detailed identification of the composition of each one.

Non-aqueous reversed-phase high performance liquid chromatography (NARP-HPLC) is very used for mono-, di-, and triglycerides analysis (Mottram and Evershed, 1996; López-López et al., 2001; Holčapek et al., 2003, 2005; Salghi et al., 2014). Especially due to the very low volatility and insolubility in aqueous solutions of triglycerides (TGs), NARP-HPLC is the most suitable technique for their analysis
(Maloumbi et al., 2015). The $\mathrm{C} 18$ grafted columns are the most suitable for the analysis of TGs with fatty acids in the range C16 to 22. A stationary phase with chain lengths similar to those of TG acyl chains maximizes the interactions and offers the greatest efficiency (Rezanka et al., 2017). Regarding the mobile phase, acetonitrile/acetone or acetonitrile/isopropanol mixtures are commonly used.

The glycerides do not have chromophores, therefore, UV detection is rarely used. However, the glycerides absorb at low wavelengths (200-210 nm), but some solvents also absorb at these wavelengths. For this reason, the universal detectors, evaporative light-scattering detector (ELSD) and charged aerosol detector (CAD) are commonly used for the detection.

Tamba Sompila et al. (2014) used NARP-HPLC for the analysis of TGs, they demonstrated that the use of the retention laws allows to identify TGs of equatorial African oils (Tamba Sompila et al., 2014). Nevertheless, their approach requires a first step to determine the fatty acid composition of the oils, and to possess standard compounds. However, HPLC coupling with mass spectrometry (MS) is generally used. HPLC-MS is a powerful tool in lipid analysis; it provides structural information with great sensitivity. Atmospheric pressure chemical ionization (APCI) is the most frequently used ionization technique for glycerides analysis. This technique allows easy coupling to NARP-HPLC and high ionization efficiency for non-polar molecules (Jakab et al., 2002; Holčapek et al., 2003; Castilho et al., 2004; Fasciotti and Pereira Netto, 2010; Rezanka et al., 2010). Atmospheric pressure photoionization (APPI) and electrospray ionization (ESI) were also used for the analysis of vegetable oils (GómezAriza et al., 2006). Gómez-Ariza et al. (2006) showed that APPI and ESI sources are complementary modes. APPI allows more sensitive detection of MG and DG fragment ions than ESI and ESI is more suitable for the detection of TGs. However, Imbert et al. (2012) demonstrated that APPI has a higher ionization capacity than APCI and ESI for lipids.

As for the characterization of PEG and PEG esters the methods used are: - for PEG, matrix-assisted laser desorption ionization-Fourier transform mass spectrometry (MALDIFTMS) (Pastor and Wilkins, 1998) and matrix-assisted laser desorption ionization-time of flight mass spectrometry (MALDI-TOF) (Jackson et al., 1997) -, for PEG esters, low 
energy collision-induced dissociation in ESI mass spectrometry (ESI-CID) with direct injection into the system (Chen et al., 2002). Chen et al. (2002) showed that low energy dissociation of PEG esters strongly dependent on the type of cation used for ionization. The structural information on the polymer chain and end groups is best obtained using $\mathrm{Li}^{+}, \mathrm{Ag}^{+}$, and other transition metal ions (Chen et al., 2002).

In the present work, we developed an analytical method by reversed phase high performance liquid chromatography for the simultaneous separation of all chemical entities within glycerides sub-classes and PEG esters of LM and OM. First, NARP-HPLC-CAD was performed using LM to optimize the experimental chromatographic conditions to reach the best selectivity. Afterwards, the developed method was applied to OM. Then, a mixture of standards molecules of MG, DG and TG was injected to check the reliability of the HPLC method. Second, NARP-HPLC-APPI-LTQ-Orbitrap was performed to allow the identification of each constituent. The same mixture of standards molecules was injected to determine the behavior fragmentation of $\mathrm{MG}, \mathrm{DG}$ and TG. Then, the identification of main peaks of LM and OM was established. Finally, a comparative study between LM and OM was conducted.

\section{Materials and methods}

\subsection{Chemical compounds}

1-oleoyl-rac-glycerol (MG 18:1), 1,2-dioleoyl-sn-glycerol (1,2-DG (18:1/18:1)), 1,3-dilinoleoyl-sn-glycerol (1,3-DG $(18: 2 / 18: 2))$ and 1,2,3-trilinoleoyl-sn-glycerol (TG (18:2/ 18:2/18:2)) were purchased from Avanti Polar Lipids (Alabama, United States). Labrafil M2125 CS ${ }^{\circledR}$ (Linoleoyl macrogolglyceride) And Labrafil M 1944 CS $^{\circledR}$ (Oleoyl macrogolglyceride) were obtained from Gattefossé (Saint-Priest, France). N-Lauroyl-D-sphingosine; dichloromethane, acetone and acetonitrile HPLC quality were purchased from SigmaAldrich (Saint-Quentin Fallavier, France).

\subsection{Chromatographic method}

HPLC instrumentation and the charged aerosol detector were from Thermo Fisher Scientific (Bremen, Germany). The nebulization temperature was set at $35^{\circ} \mathrm{C}$ and nitrogen pressure at 5 bars.

Vintage Series KR C18 column $(250 \times 4.6 \mathrm{~mm}, 5 \mu \mathrm{m})$ was from Interchim (Montluçon, France). The column was thermostated at $25^{\circ} \mathrm{C}$. The mobile phase was a mixture of acetonitrile and acetone. A mixture 97/3, acetonitrile/ acetone, $\mathrm{v} / \mathrm{v}$, was applied in the first ten minutes, an automatic gradient was applied from $10 \mathrm{~min}$ to $100 \mathrm{~min}$ until reaching $60 / 40$ of acetonitrile/acetone, $v / v$, then maintained at $60 / 40$ from 100 to $200 \mathrm{~min}$. The flow rate was set at $1 \mathrm{~mL} /$ min with automatic injection of $20 \mu \mathrm{L}$. All samples were diluted at $1 / 100$ in a mixture of acetonitrile and dichloromethane $50 / 50, \mathrm{v} / \mathrm{v}$.

In addition, to compare between LM and OM, two batches were analyzed, with three injections for each batch. In each sample the same chemical internal standard (ISTD) was added, $\mathrm{N}$-Lauroyl-D-sphingosine at $1 \mathrm{mg} / \mathrm{mL}$.

\subsection{Mass spectrometry method}

HPLC is coupled with LTQ-Orbitrap velos Pro mass spectrometer from Thermo Fisher Scientific (Bremen, Germany). The signal was acquired with Xcalibur software from Thermo Fisher Scientific. The spectrometer is a hybrid device incorporating two analyzers, a double linear ion trap (at high and low pressure) and a Fourier Transform orbital trap. The ionization source used was atmospheric pressure photoionization (APPI), using the positive-ion mode. Vaporizer temperature of the probe was set at $350{ }^{\circ} \mathrm{C}$. Sheath gas, auxiliary gas, and sweep gas flow rates were set at 40,20, and 0 (arbitrary unit) respectively. Capillary temperature was set at $325^{\circ} \mathrm{C}$ and $\mathrm{S}$-lens $\mathrm{RF}$ level at $60 \%$. The data was acquired in the mass range $\mathrm{m} / \mathrm{z} 150.00-1100$.

\subsection{Chemometrics}

\subsubsection{Processing data}

Raw data file was imported in MZmine software (MZmine 2, 2010). Displaying the total ion chromatogram (TIC) permitted to take note of the baseline level and the height of the smallest significant peak. The peak detection is a threestep process: mass detection, chromatogram building and peak deconvolution. For mass detection, we used centroid mode and noise level was set to $10^{5}$ and MS level to 1 . For chromatogram building, selected minimum time span was $1 \mathrm{~min}$ and minimum height $10^{6}$ with a $\mathrm{m} / \mathrm{z}$ tolerance of $0.001 \mathrm{~m} / \mathrm{z}$ or $5 \mathrm{ppm}$. Then, a deconvolution was conducted using the "Local minimum search" algorithm with a chromatographic threshold of $1 \%$, a search minimum in retention time (RT) range of 1 min, a minimum relative height of $5 \%$, a minimum absolute height of $10^{6}$, a minimum ratio of peak top/edge of 20 and a peak duration ranging from 0 to $5 \mathrm{~min}$. After peak deconvolution, MZmine produces a resolved peak list where the most intense isotope was considered. Peak alignment is done with join aligner method with $\mathrm{m} / \mathrm{z}$ tolerance set to 0.001 , weight for $\mathrm{m} / \mathrm{z}$ set to 20 , and the maximum allowed relative distance between two retention time values was 5\%, and score for perfectly matching RT values was 10 . After, gap filling was applied using the option same $\mathrm{RT}$ and $\mathrm{m} / \mathrm{z}$ range with $\mathrm{m} / \mathrm{z}$ tolerance of $0.001 \mathrm{~m} / \mathrm{z}$ or $5 \mathrm{ppm}$. As we chose to add a chemical standard to all samples, we normalized our data on peak area using the weighted contribution of standard compound with a $\mathrm{m} / \mathrm{z} v s$. RT balance of 3 . Our chemical internal standard of exact mass 481.449 appears at $\mathrm{m} / \mathrm{z}$ : 464.443-464.448 corresponding to ion fragment $\left[\mathrm{M}+\mathrm{H}-\mathrm{H}_{2} \mathrm{O}\right]^{+}$.

\subsubsection{Data analysis: Descriptive statistics and multivariate analysis}

From the matrix obtained after data processing by MZmine software, a new matrix was constructed, by the calculating the mean and standard deviation of $\mathrm{m} / \mathrm{z}$ corresponding to each $\mathrm{RT}$, for LM and OM.

In addition, principal component analysis (PCA) and orthogonal partial least square - discriminant analysis (OPLSDA) were performed using Simca $\mathrm{P}+$ (version 12.0.1.0, Umetrics). The analysis was carried out on 12 samples and 1327 variables (variables represent the couples RT and $\mathrm{m} / \mathrm{z}$ ). 
Prior to analysis, our data set was centered and normalized. The variation of each variable was centered so that the mean of each column is equal to 0 and scaled to unit variance (1/SD). Principal component analysis (PCA) is a multivariate technique that analyses a data table in which observations (here different Labrafils) are described by several variables (RT and $\mathrm{m} / \mathrm{z}$ ). The goal is to extract the important information from the data matrix and to find a set of new orthogonal axes called principal components. However, PCA remains a descriptive chemometric method. Therefore, OPLS-DA is used to highlight the discriminant variables explaining the difference between the groups.

\section{Results and discussion}

\subsection{Optimization of chromatographic conditions}

The optimization of chromatographic conditions was performed with LM. It was not performed with a mixture of standards as it was not possible to have all the standards because the richness of the chemical composition of LM and OM.

The gas chromatography was not considered because of the presence of the polymers (MPEGEs and DPEGEs). Nonaqueous phase mobile was used because LM and OM are not soluble in water.

Due to the low volatility, the presence of polymers and the no water solubility of LM and OM, liquid chromatography and non-aqueous phase mobile were selected for the analysis of the two ingredients. The initial operating conditions were based on the method of the TGs separation developed by Tamba Sompila et al. (2014). The first run was $60 \mathrm{~min}$ with an isocratic system 70/30, acetonitrile/acetone, $\mathrm{v} / \mathrm{v}$, using vintage Series KR C18 column $(250 \times 4.6 \mathrm{~mm}, 5 \mu \mathrm{m})$ and charged aerosol detector

In NARP-HPLC, acetonitrile is the weak solvent. It allows better resolutions and facilitates the separation of unsaturated glycerides through its interactions with electrons $\pi$ of double bonds. Acetone (or isopropanol) is the strong solvent, added in a smaller amount than the weak solvent, it allows to modulate the analysis time and the polarity of the mobile phase (Maloumbi et al., 2015; Rezanka et al., 2017).

The isocratic system acetonitrile/acetone $70 / 30 \mathrm{v} / \mathrm{v}$ was not efficient for our purpose as PEG esters overlapped with MGs between 0 to $20 \mathrm{~min}$.

A first experimental plan was established to optimize the separation of the peaks in isocratic mode, increasing the percentage of the weak solvent: a pitch of $5 \%$ of acetonitrile was considered (i.e. the mobile phase mixtures tested were: $75 /$ $25,80 / 20,85 / 15,90 / 10,95 / 5$, acetonitrile/acetone, $\mathrm{v} / \mathrm{v}$ ). Indeed, acetonitrile, in larger quantities, allowed a good resolution of less apolar products but delayed the release of highly apolar products.

Then, a gradient mode was considered to improve the analysis time and elute all constituents. Several combinations of the mobile phase and slope of eluent strength were tested. Finally, the best gradient profile was the following, for the first 10 minutes, an isocratic step acetonitrile/acetone $97 / 3 \mathrm{v} / \mathrm{v}$ was set. Following by an automatic gradient applied from $10 \mathrm{~min}$ to $100 \mathrm{~min}$, until reaching acetonitrile/acetone $60 / 40 \mathrm{v} / \mathrm{v}$. Then another isocratic step was applied from $100 \mathrm{~min}$ to $200 \mathrm{~min}$, with this last mobile phase composition acetonitrile/acetone $60 / 40 \mathrm{v} / \mathrm{v}$.

As LM and OM as both mixtures of glycerides and PEGesters, this method had be applied for LM as well for OM. The major peaks for LM and OM were separated under these improved experimental conditions (Fig. 2).

\subsection{Reliability of the developed method: relationships chemical structure/chromatographic behavior}

To highlight the relationships chemical structure/chromatographic behavior of glycerides, the same HPLC conditions retained for the analysis of LM and OM were used to analyze a mixture of standard molecules. First, MG (18:1), 1,2-DG (18:1/18:1), 1,3-DG (18:2/18:2), TG (18:2/ $18: 2 / 18: 2)$ standards were injected separately to make sure of the retention time (RT) of each one. Second, a mixture of all the standards was injected, the obtained chromatogram is shown in Figure 3. MG was eluted first followed by DGs then TGs. RT increased with increasing molecular weight. For molecules of near molecular weight, as DG (18:1/8:1) and DG (18:2/18:2), the molecule with more unsaturated bonds would have a shorter retention time.

Comprehensively, the retention increased with increasing of the total carbon number $(\mathrm{CN})$. For the same $\mathrm{CN}$, the retention decreased according to the number of double bonds (DB). It is known that NARP-HPLC mainly separates the different glycerides according to their equivalent carbon number $(\mathrm{ECN})$, which is calculated as following, $\mathrm{ECN}=\mathrm{CN}$ - (2× DB)(Holčapek et al., 1999; Lísa et al., 2007, 2011; Rezanka et al., 2017).

To highlight the relationships chemical structure/chromatographic behavior of PEG-esters, the NARP-HPLC-APPIMS was applied to LM and OM as no standards of pure PEGesters were available. Using mass spectrometry (see Sect. 3.3.2), it has been possible to determine the elution order of the polymers. Mainly it depends first on the number of esters groups (mono-PEG-esters eluted before di-PEG-esters), second the number of double bonds (DB) on the fatty acid moieties (monounsaturated compounds eluted after diunsaturated compounds). Thirdly, MPEGEs with various number of ethyleneglycol units were eluted under the same chromatographic peak, while for the DPEGEs, the retention decreased according to the number of ethyleneglycol units.

\subsection{Characterization of mono-, di- and triglycerides as well as PEG esters by HPLC-APPI-LTQ-Orbitrap}

\subsubsection{Characterization of mono-, di- and triglycerides}

APPI is recently introduced technique, where a highly energetic photon is used to effect generation of charged ion species. In comparison to APCI, APPI offered lower detection limits, highest sensitive and the same fragmentation pattern for mono, di and triacylglycerols (Holčapek et al., 1999; GómezAriza et al., 2006; Rezanka et al., 2010).

Mass spectra of MG (18:1), 1,2-DG (18:1/18:1), 1,3-DG $(18: 2 / 18: 2)$ and TG $(18: 2 / 18: 2 / 18: 2)$ are shown in Figure 5. The APPI mass spectra exhibited the protonated molecular ion $[\mathrm{M}+\mathrm{H}]^{+}$for each glyceride. So, the molecular masses of the different compounds can be easily determined. The APPI-MS 

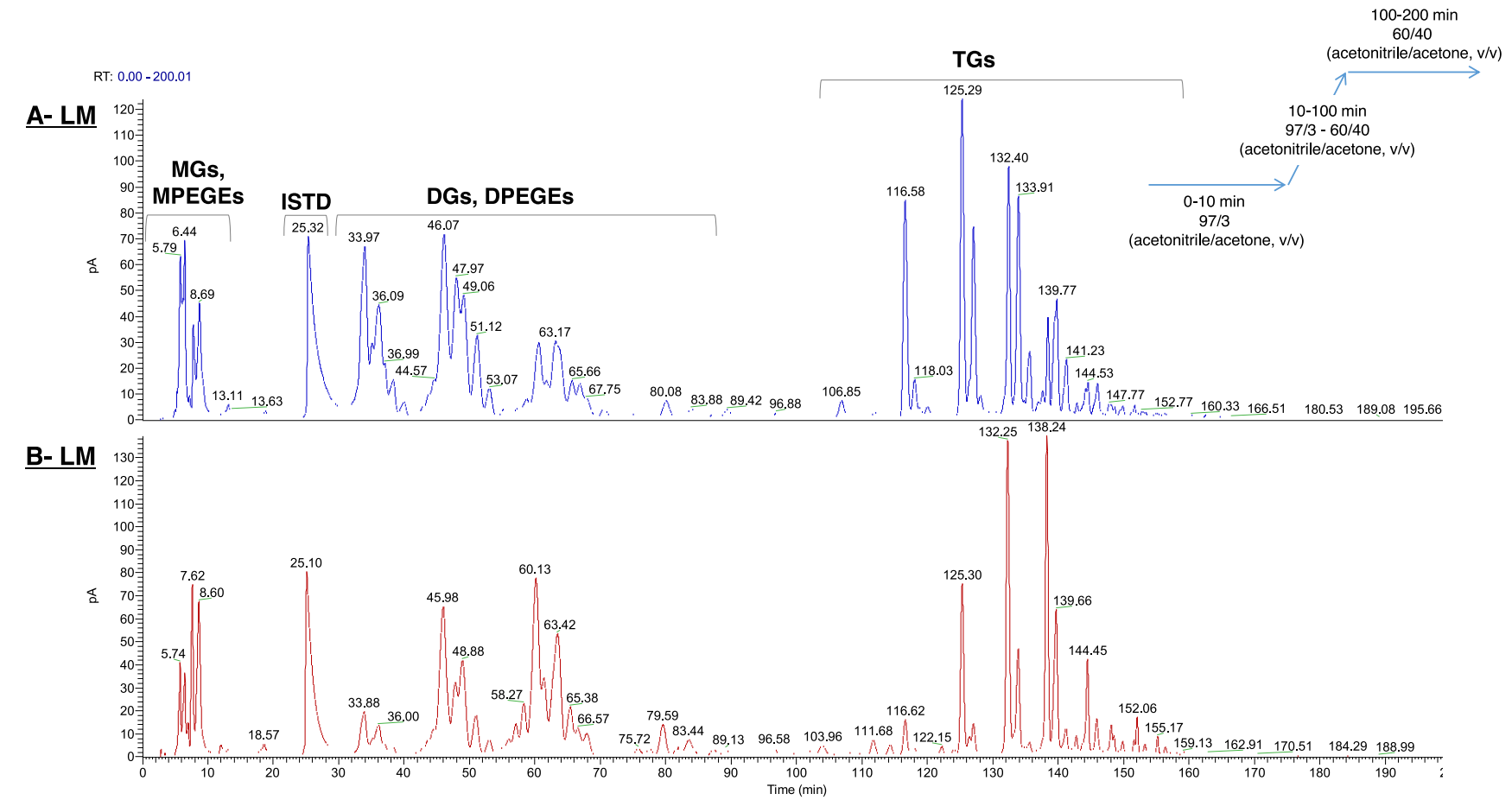

Fig. 2. NARP-HPLC-CAD analysis of LM and OM with optimized chromatographic conditions. 97/3, acetonitrile/acetone, v/v was set for the first 10 minutes, from $10 \mathrm{~min}$ to $100 \mathrm{~min}$ an automatic gradient was applied until reaching 60/40, acetonitrile/acetone, v/v, and an isocratic system was applied from $100 \mathrm{~min}$ to $200 \mathrm{~min}$ with a mixture $60 / 40$, acetonitrile/acetone $\mathrm{v} / \mathrm{v}$.

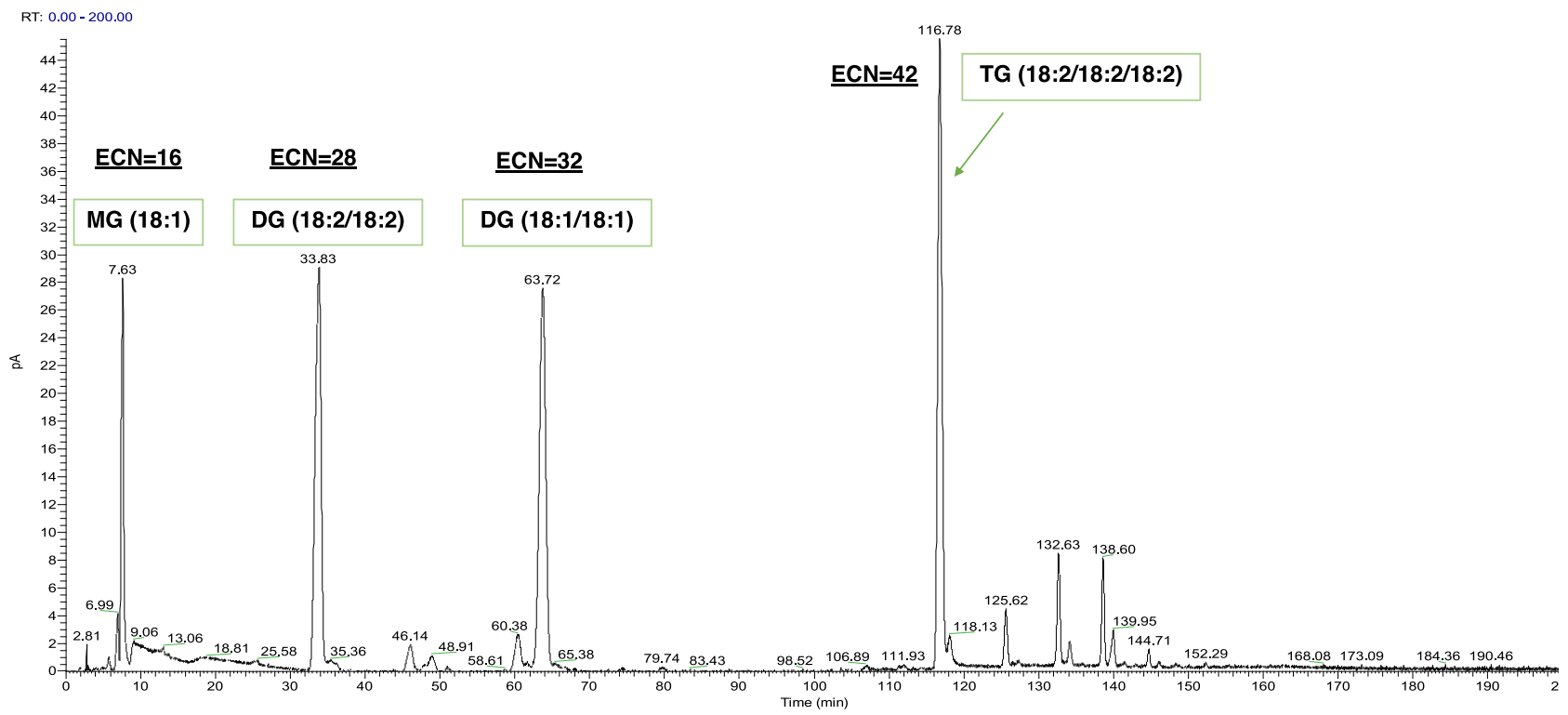

Fig. 3. NARP-HPLC-CAD analysis of a mixture of MG (18:1), 1,2-DG (18:1/18:1), 1,3-DG (18:2/18:2) and TG (18:2/18:2/18:2) standards. MG, DGs and TG were eluted in order of increasing ECN.

ionization and fragmentation patterns of $\mathrm{MG}, \mathrm{DG}$ and $\mathrm{TG}$ are as described by RP-HPLC-APCI (Holčapek et al., 1999; Gómez-Ariza et al., 2006; Rezanka et al., 2010).

- APPI-MS spectrum of MG $(18: 1)$ presents the protonated molecular ion $[\mathrm{M}+\mathrm{H}]^{+}(\mathrm{m} / \mathrm{z}$ 357.299) and fragment ions: the protonated molecule loses a molecule of water $\left[\mathrm{M}+\mathrm{H}-\mathrm{H}_{2} \mathrm{O}\right]^{+}(\mathrm{m} / \mathrm{z} 339.289)$. Then, we see its typical fatty acid (18:1) i.e. $[\mathrm{RCO}]^{+}(\mathrm{m} / \mathrm{z} 265.252)$ and which then loses a molecule of water $\left[\mathrm{RCO}-\mathrm{H}_{2} \mathrm{O}\right]^{+}(\mathrm{m} / \mathrm{z}$ 247.241) (Fig. 4A);

- Similarly, APPI-MS spectra of 1,2-DG (18:1/18:1) and 1,3DG $(18: 2 / 18: 2)$ give the protonated molecular ions $[\mathrm{M}+\mathrm{H}]^{+}(\mathrm{m} / \mathrm{z} 621.540$ and $\mathrm{m} / \mathrm{z} 617.509$ respectively) and fragment ions: the protonated molecules lose a 

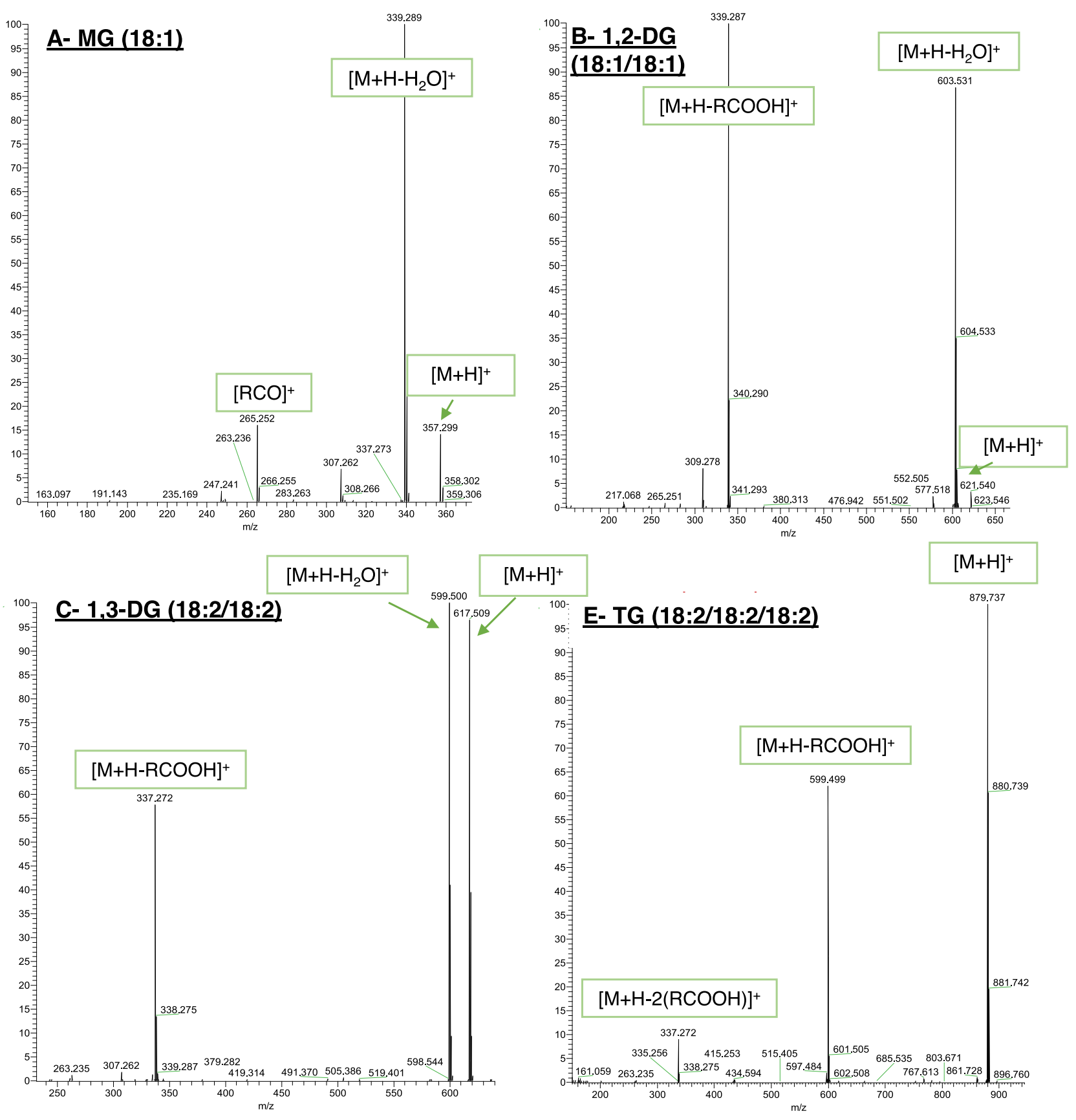

Fig. 4. APPI-MS spectra in positive-ion mode of MG (18:1) (A); DG (18:1/18:1) (B); DG (18:2/18:2) (C); and TG (18:2/18:2/18:2) (D).

molecule of water $\left[\mathrm{M}+\mathrm{H}-\mathrm{H}_{2} \mathrm{O}\right]^{+}(\mathrm{m} / \mathrm{z} 603.531$ of $1,2-$ DG (18:1/18:1) and $\mathrm{m} / \mathrm{z} 599.500$ of $1,3-\mathrm{DG}(18: 2 / 18: 2))$. Then by losing a fatty acid (18:1 for $1,2-\mathrm{DG}(18: 1 / 18: 1)$ and 18:2 for 1,3-DG (18:2/18:2)), their characteristic MG (18:1) and $\mathrm{MG}(18: 2)$ are obtained i.e. $[\mathrm{M}+\mathrm{H}-$ $\mathrm{RCOOH}^{+}(\mathrm{m} / \mathrm{z} 339.287$ and $\mathrm{m} / \mathrm{z} 337.272)$. Their fatty acids (18:1 and 18:2) i.e. $\left[\mathrm{RCO}^{+}(\mathrm{m} / \mathrm{z} 265.251\right.$ and $\mathrm{m} / \mathrm{z}$ $263.235)$ and $\left[\mathrm{RCO}-\mathrm{H}_{2} \mathrm{O}\right]^{+}(\mathrm{m} / \mathrm{z} \quad 247.240$ and $\mathrm{m} / \mathrm{z}$ 245.226) are also observed (Figs. $4 \mathrm{~B}$ and $4 \mathrm{C}$ ).

It was possible to detect and identify the other DGs present at low quantities in the standard mixture, DG $(18: 1 / 18: 2)$ at $46.1 \mathrm{~min}$ and $1,3-\mathrm{DG}(18: 1 / 18: 1)$ at $60.4 \mathrm{~min}$ (Fig. 4). The isomeric 1,2-DG (18:1/18:1) was distinguished from 1,3-DG $(18: 1 / 18: 1)$, with the same ECN, 1,3-DG was eluted before 1,2-DG, as it has been shown by Holčapek et al. (Holčapek et al., 1999). The hydrophobic interactions with the stationary phase for the positional isomer 1,2-DG are stronger compared to those of the 1,3-isomer, because of the position of the central hydroxy group (Holčapek et al., 1999).

- APPI-MS spectrum of TG $(18: 2 / 18: 2 / 2)$ provides the protonated molecular ions $[\mathrm{M}+\mathrm{H}]^{+}(\mathrm{m} / \mathrm{z} 879.737)$ and also fragment ions: the protonated molecule loses a fatty acid (18:2) and gives its typical DG (18:2/18:2) i.e. $[\mathrm{M}+\mathrm{H}-\mathrm{RCOOH}]^{+}(\mathrm{m} / \mathrm{z} \quad 599.499)$. The protonated molecule loses two fatty acid (18:2) and gives its typical 


\section{A- MPEGE (18:2)}

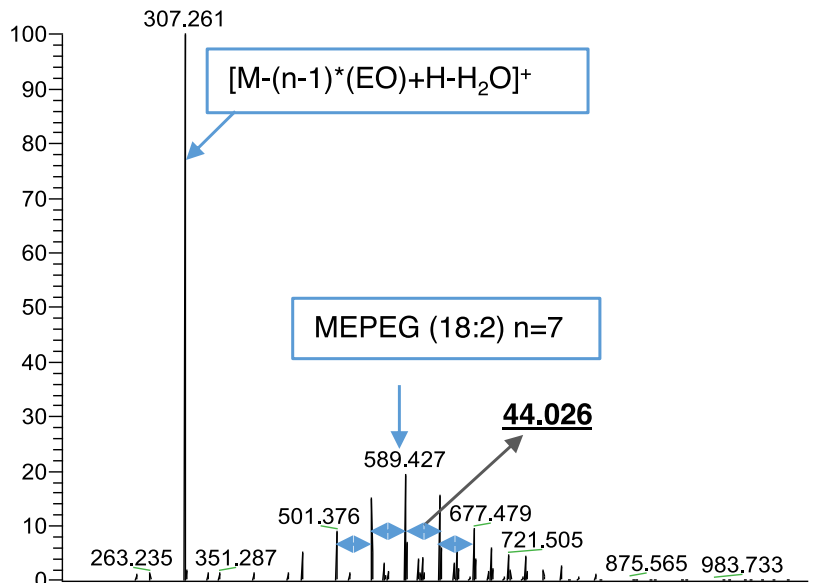

\section{DPEGE (18:2/18:2)}

100 手

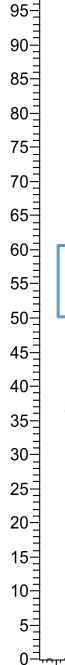

\section{B- MPEGE (18:1)}
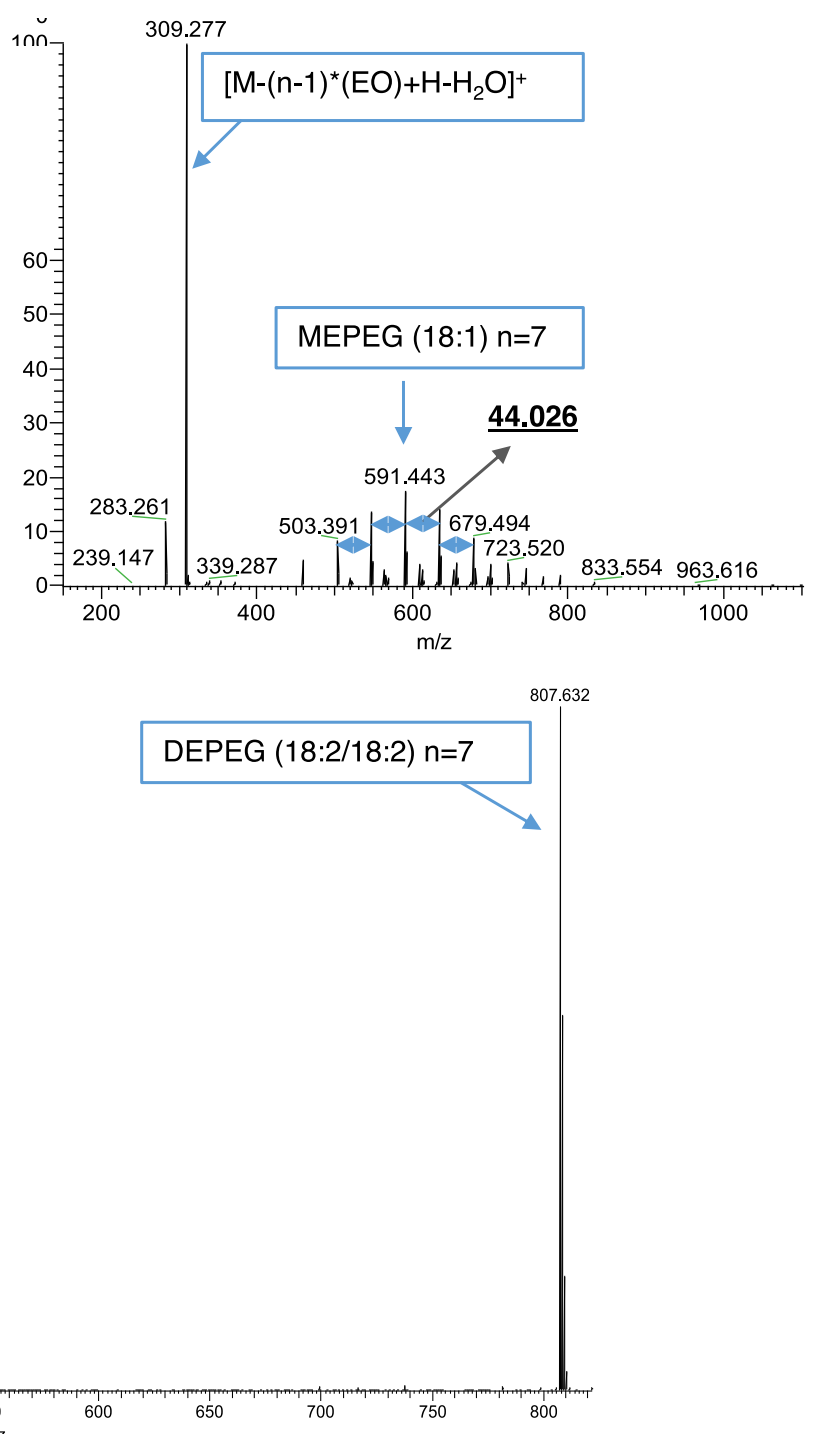

Fig. 5. APPI-MS spectra in positive-ion mode of MPEGE (18:2) (A); MPEGE (18:1) (B); and DPEGE (18:1/18:2) (C).

$\mathrm{MG}(18: 2)$ i.e. $[\mathrm{M}+\mathrm{H}-2(\mathrm{RCOOH})]^{+}(\mathrm{m} / \mathrm{z} \quad 337.272)$ (Fig. 5D).

Other triglycerides were present in the standard mixture, peaks at 125.6, 132.6 and $138.6 \mathrm{~min}$ (Fig. 4). Using protonated molecular and fragment ions, the TGs were identified and are TG (18:2/18:2/18:1), TG (18:1/18:2/18:1) and TG (18:1/18:1/18:1). The TGs are eluted in order of increasing ECN (44, 46 and 48).

The position of the substitution of fatty acids in TGs was determined from fragmentation of $\mathrm{TG}$, considering the diglyceride fragments $\mathrm{m} / \mathrm{z}$. It has been demonstrated that the ratio of the abundance of these fragment ions could be used to identify the sn-2 and sn-1 (or sn-3) positions (Mottram and Evershed, 1996). The relative abundance of $[\mathrm{M}+\mathrm{H}-$ $\mathrm{RCOOH}]^{+}$ion fragment corresponding to loss of fatty acid from sn-2 position is less than the relative abundance of $[\mathrm{M}+\mathrm{H}-\mathrm{RCOOH}]^{+}$ion fragment due to loss fatty acid from sn-1 (or sn-3) (Mottram and Evershed, 1996).

\subsubsection{Characterization of PEG esters}

APPI-MS ionization and fragmentation profiles of PEG esters are highlighted as follows:

For each mono-PEG ester, the protonated molecular ion $[\mathrm{M}+\mathrm{H}]^{+}$and the fragment ion $\left[\mathrm{M}-(n-1)(\mathrm{EO})+\mathrm{H}-\mathrm{H}_{2} \mathrm{O}\right]^{+}$ were observed. The MPEGEs mass distribution was exhibited as adjacent protonated molecular ions $[\mathrm{M}+\mathrm{H}]^{+}$separated by 44.026 Da, consistent to the mass of the repeat unit, ethylene oxide (EO), as observed with ESI mass spectrometry (Chen et al., 2002).

For example, mass spectrum of MPEGEs (18:2) presents: the different protonated molecular ions corresponding to MPEGE with different repeat units (m/z 633.453, m/z 589.427 and $\mathrm{m} / \mathrm{z} 545.401 \ldots$ corresponding to $n=8, n=7$ and $n=6 \ldots$ respectively), and $\mathrm{m} / \mathrm{z} 307.261$ typical to (MPEGE) $n_{=1}$ with C18:2 fatty acid moiety i.e. $\left[\mathrm{M}-(n-1)(\mathrm{EO})+\mathrm{H}-\mathrm{H}_{2} \mathrm{O}\right]^{+}$ (Fig. 5A). Similarly, for MPEGE (18:1), mass spectrum 
provides: the protonated molecular ions, $\mathrm{m} / \mathrm{z} 635.469, \mathrm{~m} / \mathrm{z}$ 591.443 and $\mathrm{m} / \mathrm{z} 547.417 \ldots$ corresponding to $n=8, n=7$ and $n=6 \ldots$ respectively; and $\mathrm{m} / \mathrm{z} 309.277$ typical to MPEGEs with $\mathrm{C} 18: 1$ fatty acid moiety i.e. $\left[\mathrm{M}-(n-1)(\mathrm{EO})+\mathrm{H}-\mathrm{H}_{2} \mathrm{O}\right]^{+}$ (Fig. 5B).

For each di-PEG ester, the protonated molecular ion $[\mathrm{M}+\mathrm{H}]^{+}$and fragment ion $[\mathrm{M}-(n-1)(\mathrm{EO})+\mathrm{H}-\mathrm{RCOOH}]^{+}$ typical to di-ethylene glycol esters i.e. (DPEGE) $n_{=1}$ were observed.

For example, DPEGE (18:2/18:2), mass spectrum provides: the protonated molecular ion, $\mathrm{m} / \mathrm{z} 807.632$ corresponding to DPEGE with 7 repeat units; and $\mathrm{m} / \mathrm{z} 307.263$ characteristic to (MPEGE) $n=1$ with $\mathrm{C} 18: 2$ fatty acid moiety i.e. $[\mathrm{M}-(n-1)(\mathrm{EO})+\mathrm{H}-\mathrm{RCOOH}]^{+}$(Fig. $\left.5 \mathrm{C}\right)$.

\subsection{Identification of constituents of linoleoyl and oleoyl macrogolglycerides}

MGs, DGs, TGs, MPEGEs and DPEGEs were identified for LM and OM as described above, exploiting the retention time, protonated molecular ion and typical fragment ions for each molecule.

The chromatograms of LM and OM can be divided into three segments, the first one being from 0 to $10 \mathrm{~min}$, the second from $30 \mathrm{~min}$ to $70 \mathrm{~min}$ and the third from $115 \mathrm{~min}$ to $150 \mathrm{~min}$. For both products, the first package represents MGs and MPEGEs, the second DGs and MPEGEs and the third TGs. Retention times were obtained after alignment and normalization of all peaks of LM and OM chromatograms (for more details see Supplementary data 1, 2 and 3).

The chemical species identified in the first segment (from 0 to $10 \mathrm{~min})$ were MG (18:1) and MG (18:2) as well as MPEGE (18:1) and MEPEG (18:2). As expected, MG (18:2) is eluted before MG (18:1). Regarding mono-PEG esters, MPEGE $(18: 2)$ is eluted after MG (18:2) and MPEGE (18:1) after MG (18:1). The mass distributions with repeat units from $n=4$ to $n=11$ were identified on the mass spectra for MPEGE (18:1) and MPEGE (18:2).

In the second segment (from $30 \mathrm{~min}$ to $70 \mathrm{~min}$ ) six DGs were identified. 1,2 and 1,3-DG (18:2/18:2), 1,2 and 1,3-DG (18:1:18:2), and 1,2 and 1,3-DG (18:1/18:1). DGs are eluted in order of increasing ECN (DG (18:2/18:2) < DG (18:1:18:2) < DG (18:1/18:1)) and DGs with the same ECN, 1,2-isomer is eluted after 1,3-isomer. 30 DPEGEs were identified: DPEGE (18:2/18:2), DPEGE (18:1/18:2) and DPEGE (18:1/18:1), with repeat units from $n=3$ to $n=12$ for each of them. DPEGEs (18:2/18:2) were eluted first followed by DPEGEs (18:1/18:2) then DPEGEs $(18: 1 / 18: 1)$ eluted. Then, the different DPEGEs were eluted in order of decreasing repeat units.

APPI allowed the identification of ten TGs in the last package (from $115 \mathrm{~min}$ to $150 \mathrm{~min}$ ). TGs separation followed ECNs and TGs with the same ECN, called critical pairs were also separated, as TG $(18: 2 / 18: 2 / 18: 1)$ and TG $(18: 2 / 18: 2 /$ $16: 0)(\mathrm{ECN}=44)$, TG $(18: 1 / 16: 0 / 18: 2)$ and TG $(18: 2 / 16: 0 /$ $16: 0)(\mathrm{ECN}=46)$, and TG $(18: 1 / 18: 1 / 18: 1)$ and TG $(18: 1 / 16: 0 /$ 18:1) $(\mathrm{ECN}=48)$. Indeed, under optimized conditions, NARPHPLC separates some critical pairs.9,12,24 NARP-HPLC can also separate some regioisomers16, it was found that symmetrical TGs elute before the corresponding asymmetrical TGs.28 In our study, the peak at $132.4 \mathrm{~min}$ correspond to TG
(18:1/18:2/18:1) is well separated from the peak at $133.6 \mathrm{~min}$, correspond to its regioisomer TG (18:1/18:1/18:2) (Fig. 6).

\subsection{Comparative study between linoleoyl and oleoyl macrogolglycerides}

MG, DGs and TG injected at the same concentration (1 mg/ $\mathrm{mL}$ ), had different response factors (R (i)): $\mathrm{R}(\mathrm{MG})<\mathrm{R}(\mathrm{DG})$ $<\mathrm{R}$ (TG). The response factors of DG (18:1/18:1) and DG $(18: 2 / 18: 2)$ had the same order. (Tab. 1) Therefore, in the samples of LM and OM, the relative amounts of the different lipid classes (MGs, DGs and TGs) cannot be compared. The comparison can only be done between the lipid sub-classes, within MGs or DGs or TGs.

The peak areas of LM and OM were normalized, to the peak area (ion fragment $[\mathrm{M}+\mathrm{H}-\mathrm{H} 2 \mathrm{O}]^{+}$) of ISTD (see the Sect. 2.4.1). From the matrix obtained after data processing, a new matrix was constructed, by calculating the mean and standard deviation of relative intensities of $\mathrm{m} / \mathrm{z}$ corresponding to each RT, for LM and OM. The comparison of the two ingredients was performed on the majority ion $(\mathrm{m} / \mathrm{z})$ of each constituent (Fig. 7, Supplementary data 4). For the glycerides, we observed that the majority ion was $[\mathrm{M}+\mathrm{H}]^{+}$above four unsaturations, otherwise it was $\left[\mathrm{M}+\mathrm{H}-\mathrm{H}_{2} \mathrm{O}\right]^{+}$for $\mathrm{MGs}$ and DGs or $[\mathrm{M}+\mathrm{H}-\mathrm{RCOOH}]^{+}$for TGs. For the PEG-esters, the majority ion was $[\mathrm{M}+\mathrm{H}]^{+}$. (Supplementary data 4)

The Figure 7 shows that LM and OM have the same qualitative composition. The difference between the two ingredients is the relative amounts of each compound within each sub-classes of glycerides and PEG-esters.

LM contains more MG (18:2) and DGs (18:2/18:2) than OM. OM contains more MG (18:1) and DGs (18:1/18:1) than LM. However, DGs $(18: 1 / 18: 2)$ are at the same amount for LM and OM. Regarding TGs, LM contains more TG (18:2/18:2/ 18:2), TG (18:2/18:2/18:1), TG (18:2/18:2/16:0) and TG $(18: 2 / 16: 0 / 16: 0)$ than OM. OM contains more TG $(18: 1 / 18: 1 /$ 18:1), TG (18:1/18:2/18:1), TG (18:1/18:0/18:1) and TG (18:1/16:0/18:1) than LM (Fig. 7A).

LM contains more MPEGEs (18:2) and DPEGEs (18:2) than OM. OM contains more MPEGEs (18:1) and DPEGEs $(18: 1 / 18: 1)$ than LM. DPEGEs $(18: 1 / 18: 2)$ are at the same amount for LM and OM (Fig. 7B).

\subsection{PCA and OPLS-DA results}

PCA was carried out for the two macrogolglycerides. As mentioned in the Section 2.2, for each macrogolglyceride, two batches were analyzed, with three injections for each batch. The first two principal components accounted for $66 \%$ of the variance. The 1 st principal component $\mathrm{PC} 1$ explained $53 \%$ of variance and the 2 nd principal component PC2 13\% of variance.

The projection of samples (score plot) on the 1st and 2nd components is presented in Figure 8. 1st component represents the chemical composition, the 2 nd component represents the batch. PC1 separated the two macrogolglycerides into two distinct groups and PC2 separated batch 1 and batch 2 for both LM and OM. These two pharmaceutical ingredients were obtained, from corn oil for LM and from apricot kernel oil for $\mathrm{OM}$, by a manufacturing process standardized by the supplier. 


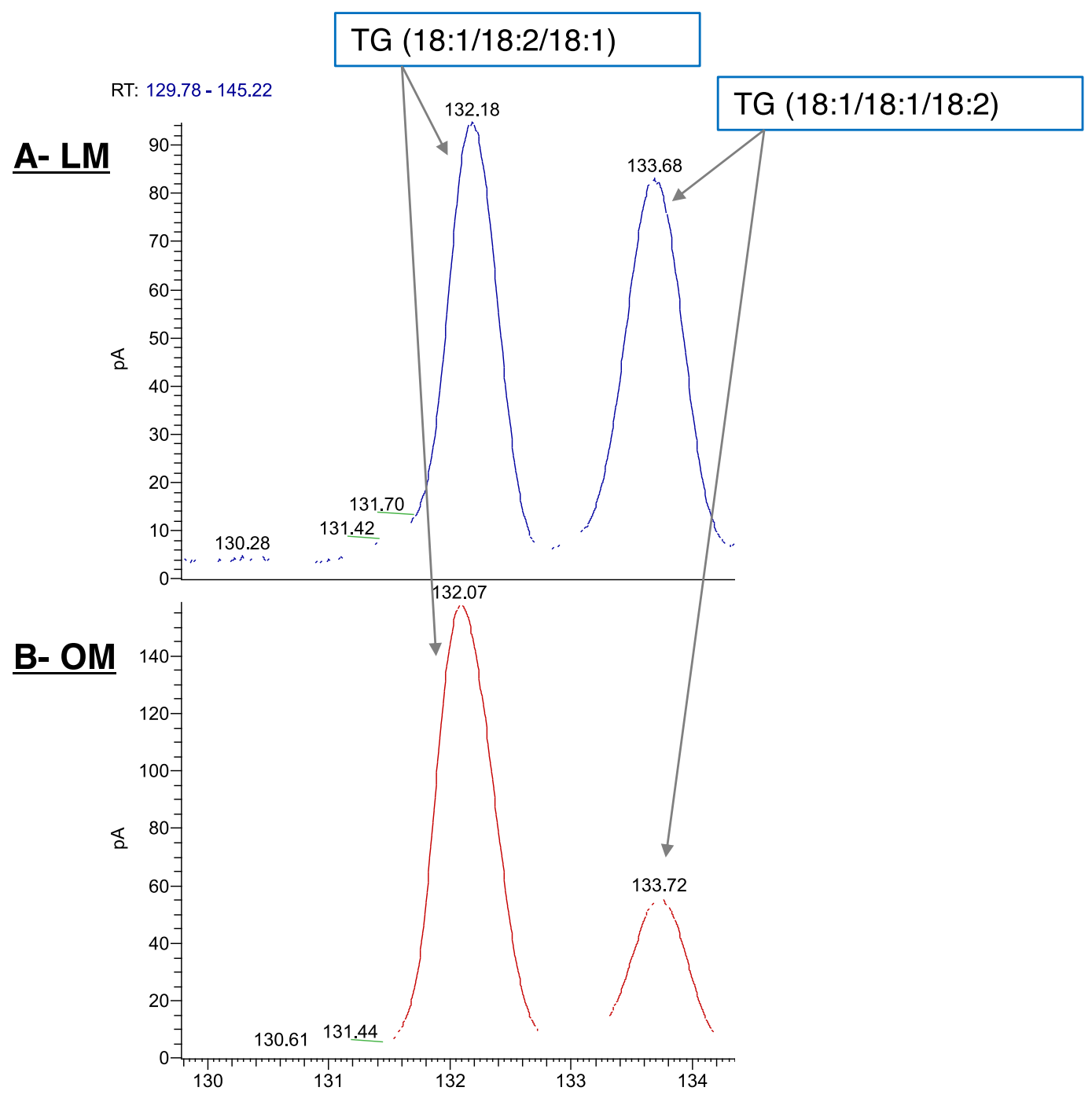

Fig. 6. Separation of two regioisomers TG (18:1/18:2/18:1) and TG (18:1/18:1/18:2) by NARP-HPLC.

Table 1. Response factors of MG, DGs and TG injected at the same concentration $(1 \mathrm{mg} / \mathrm{mL})$.

\begin{tabular}{ll}
\hline Molecules & Response factors \\
\hline MG (18:1) & $3.71 \times 10^{6}$ \\
DG $(18: 1 / 18: 1)$ & $6.81 \times 10^{7}$ \\
DG $(18: 2 / 18: 2)$ & $3.92 \times 10^{7}$ \\
TG $(18: 2 / 18: 2 / 18: 2)$ & $1.25 \times 10^{8}$ \\
\hline
\end{tabular}

As the raw materials are of vegetable-origin, then, there is a variability of the composition of corn and apricot kernel oils. Therefore, the batches of finished goods can have a relative variability of their compositions. This explains the separation, in the score plot, of the two batches analyzed for LM and OM.

OPLS-DA was carried out to highlight the discriminant variables explaining the difference between the two groups. Splot displayed at the lower part an overexpression for LM and at the upper part an overexpression for OM. Table 2 summarizes the expressed latent variables. For each variable, an identification of the molecule specie was performed. For LM, a higher presence of MEPEG, DG, DEPEG and TG of linoleic acid (18:2 carbon chain) is highlighted and for OM, MEPEG, DG, DEPEG and TG of oleic acid (18:1 carbon chain). In addition, for LM, a higher presence of TG (18:2/ 18:2/18:1), (18:2/18:2/16/0), TG (18:1/16:0/18:2) and TG $(18: 2 / 16: 0 / 16: 0)$ is highlighted and for OM, TG $(18: 1 / 18: 2 /$ $18: 1)$, TG (18:1/18:0/18:1) and (18:1/16:0/18:1).

\section{Conclusion}

NARP-HPLC method developed in this work allowed not only the separation of mono-, di- and triglycerides, but also the separation of mono- and di-PEG esters. Then, the characterization of the fine composition for both linoleoyl macrogolglyceride (LM) and oleoyl macrogolglyceride (OM), two pharmaceutical ingredients widely used, can be accessed at the molecular level, mainly the microheterogeneity of the 

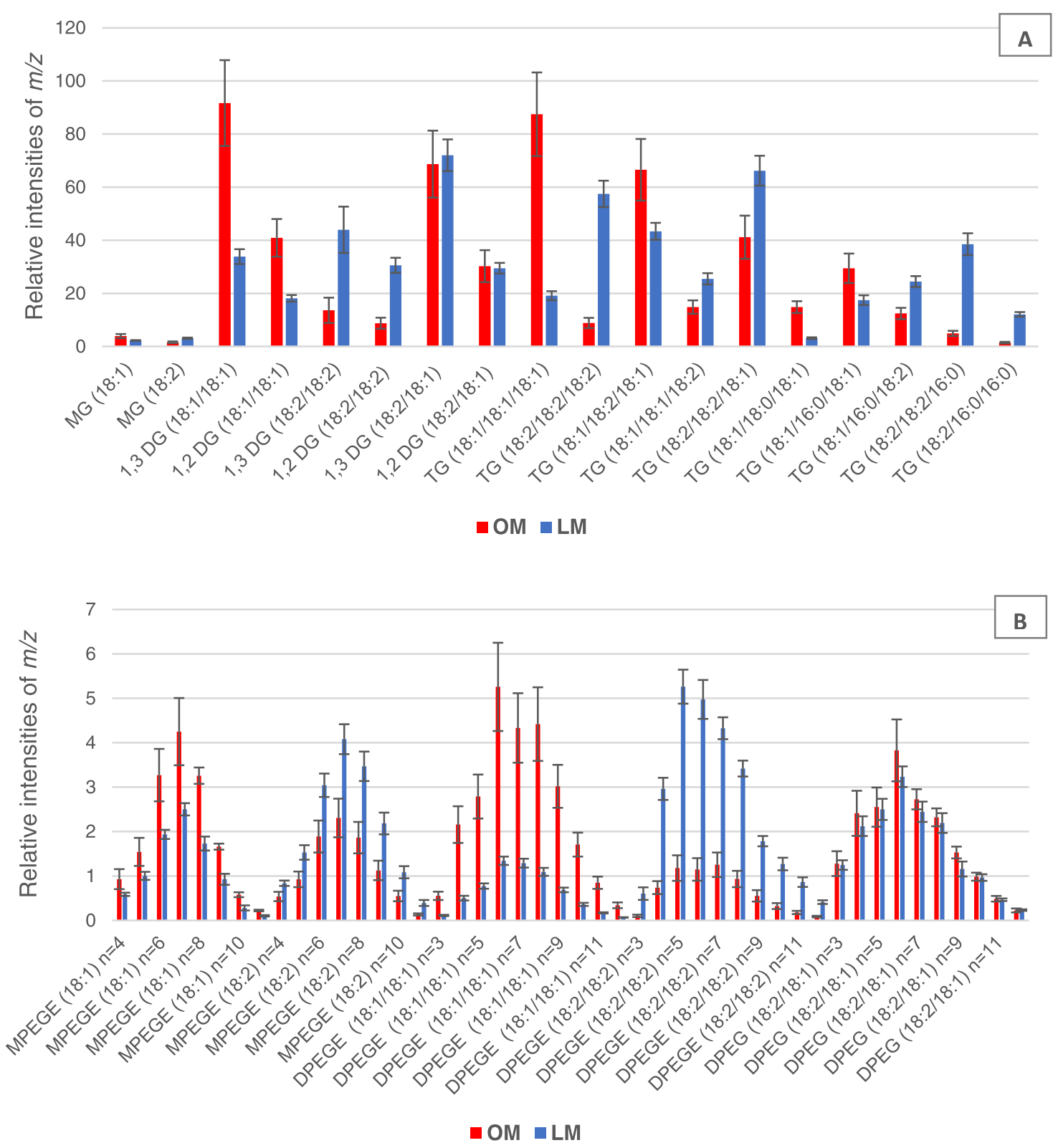

Fig. 7. Comparative profile of LM and OM: relative intensities of majority ion $\mathrm{m} / \mathrm{z}$ (mean and standard deviation) for each compound. A: corresponds to monoglycerides, diglycerides and triglycerides. B: corresponds to mono- and di-PEG esters.

The relative intensities of $\mathrm{m} / \mathrm{z}$ are the means of the normalized peak areas of the two batches of LM and OM injected in triplicate.

glycerides sub-classes and the number of ethylene glycol units within PEG-esters.

The coupling HPLC-APPI allowed the identification of the most peaks of LM and OM. The constituents identified in LM and $\mathrm{OM}$ were MG (18:1) and MG (18:2). 1,2-DG (18:1/18:1) and 1,3-DG (18:1/18:1); 1,2-DG (18:2/18:2) and 1,3-DG (18:2/18:2); 1,2-DG (18:1/18:2) and 1,3-DG (18:1/18:2). TG $(18: 1 / 18: 1 / 18: 1)$, TG $(18: 2 / 18: 2 / 18: 2)$ and 8 mixed TGs of (18:1), (18:2), (16:0) and (18:0). MPEGEs (18:1) and MPEGEs (18:2), with number of units of ethylene oxide from $n=4$ to $n=11$. DPEGEs $(18: 1 / 18: 1)$, DPEGEs $(18: 2 /$ 18:2) and DPEGEs (18:1/18:2), with number of units of ethylene oxide from $n=3$ to $n=12$.
MGs, DGs and TGs were eluted in order of increasing ECN. For the same ECN, some regioisomers and critical pairs were also separated. 1,3-isomers of DG were eluted before 1,2isomers. Within the TG sub-class, the position and the number of unsaturated bonds affected the retention times. Thus, TG $(18: 1 / 18: 1 / 18: 2)$ was eluted after TG (18:1/18:2/18:1). Moreover, 3 critical pairs (TG (18:2/18:2/18:1) and TG (18:2/18:2/16:0), TG (18:1/16:0/18:2) and TG (18:2/16:0/ 16:0), and TG (18:1/18:1/18:1) and TG (18:1/16:0/18:1)) were well separated, showing the discriminant power of the method.

For PEG esters, MPEGEs were eluted before DPEGEs. Then, PEGEs were eluted by decreasing the number of double bonds (DB) on the fatty acid moieties (monounsaturated 


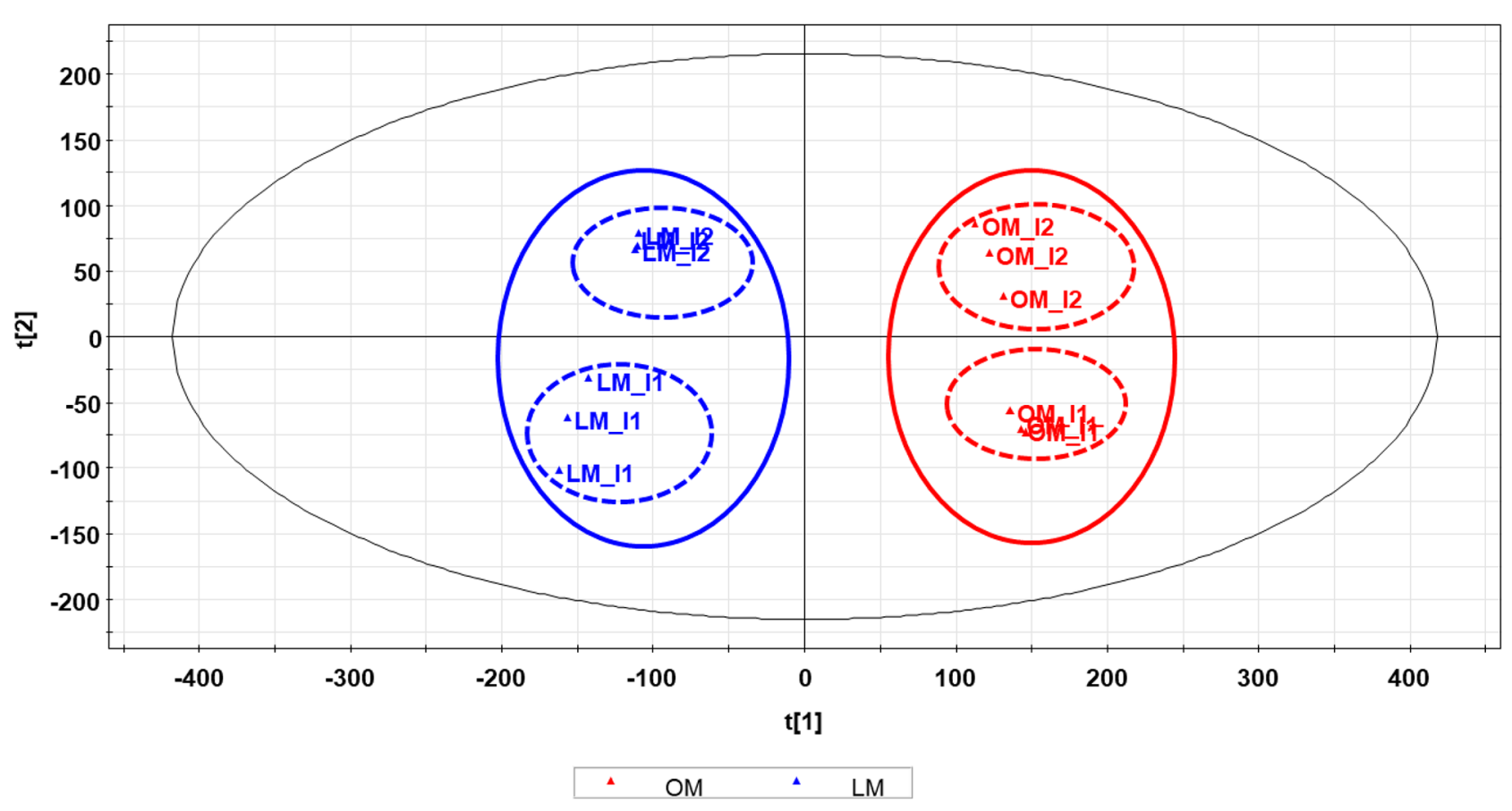

Fig. 8. Score plot of LM (blue) and OM (red). 11 and 12 represent the batch 1 and the batch 2, respectively, for both LM and OM.

Table 2. OPLS-DA: variables expressed in the upper and lower part of the S-plot.

\begin{tabular}{|c|c|c|c|c|c|c|c|}
\hline \multicolumn{4}{|c|}{ LM (Lower part of S-plot) } & \multicolumn{4}{|c|}{ OM (Upper part of S-plot) } \\
\hline 6.4 & 307.262 & $\begin{array}{l}{\left[\mathrm{M}-(n-1)^{*}(\mathrm{EO})\right.} \\
\left.+\mathrm{H}-\mathrm{H}_{2} \mathrm{O}\right]^{+}\end{array}$ & MEPEG (18:2) & 8.7 & 309.277 & $\begin{array}{l}{\left[\mathrm{M}-(n-1)^{*}(\mathrm{EO})\right.} \\
\left.+\mathrm{H}-\mathrm{H}_{2} \mathrm{O}\right]^{+}\end{array}$ & MEPEG (18:1) \\
\hline 33.6 & 599.501 & {$\left[\mathrm{M}+\mathrm{H}-\mathrm{H}_{2} \mathrm{O}\right]^{+}$} & DG $(18: 2 / 18: 2)$ & 60.2 & 603.533 & {$\left[\mathrm{M}+\mathrm{H}-\mathrm{H}_{2} \mathrm{O}\right]^{+}$} & DG $(18: 1 / 18: 1)$ \\
\hline 35.9 & 307.262 & $\begin{array}{l}{\left[\mathrm{M}-(n-1)^{*}(\mathrm{EO})\right.} \\
+\mathrm{H}-\mathrm{RCOOH}]^{+}\end{array}$ & DEPEG (18:2/18:2) & 63.1 & 309.278 & $\begin{array}{l}{\left[\mathrm{M}-(n-1)^{*}(\mathrm{EO})\right.} \\
+\mathrm{H}-\mathrm{RCOOH}]^{+}\end{array}$ & DEPEG $(18: 1 / 18: 1)$ \\
\hline 125.4 & 881.757 & {$[\mathrm{M}+\mathrm{H}]^{+}$} & TG $(18: 2 / 18: 2 / 18: 1)$ & 132.3 & 883.772 & {$[\mathrm{M}+\mathrm{H}]^{+}$} & TG $(18: 1 / 18: 2 / 18: 1)$ \\
\hline 126.9 & 855.741 & {$[\mathrm{M}+\mathrm{H}]^{+}$} & TG $(18: 2 / 18: 2 / 16: 0)$ & 139.7 & 577.517 & $\begin{array}{l}\mathrm{M}+\mathrm{H}-\mathrm{RCOOH}]^{+} \\
(\mathrm{DG} 18: 1 / 16: 0) \\
{[\mathrm{M}+\mathrm{H}-\mathrm{RCOOH}]^{+}} \\
(\mathrm{DG} 18: 1 / 18: 1)\end{array}$ & TG (18:1/16:0/18:1) \\
\hline 133.8 & $\begin{array}{l}575.501 \\
577.517\end{array}$ & $\begin{array}{l}{[\mathrm{M}+\mathrm{H}-\mathrm{RCOOH}]^{+}} \\
(\mathrm{DG} 18: 2 / 16: 0) \\
{[\mathrm{M}+\mathrm{H}-\mathrm{RCOOH}]^{+}} \\
(\mathrm{DG} 18: 1 / 16: 0)\end{array}$ & TG (18:1/16:0/18:2) & 144.4 & 605.55 & $\begin{array}{l}{[\mathrm{M}+\mathrm{H}-\mathrm{RCOOH}]^{+}} \\
(\mathrm{DG} 18: 1 / 18: 1) \\
{[\mathrm{M}+\mathrm{H}-\mathrm{RCOOH}]^{+}} \\
(\mathrm{DG} 18: 1 / 18: 0)\end{array}$ & TG $(18: 1 / 18: 0 / 18: 1)$ \\
\hline
\end{tabular}

compounds eluted after diunsaturated compounds). Regarding the mass distribution of PEG esters, it was detected under the same peak for MPEGEs (18:1), as well as for MPEGEs (18:2). This highlights that the number of ethylene glycol units did not impact the retention of MPEGEs. For Di-PEG esters, the presence of the two fatty acid moieties allowed a better separation compared to MPEGEs and the compounds of this sub-class were eluted in order of decreasing of number of units of ethylene oxide.
It can be concluded that NARP-HPLC combined with APPI-MS is a suitable tool to characterize the two macrogolglycerides. HPLC-APPI allowed us to obtain the detailed chemical composition of LM and OM. These two pharmaceutical ingredients have the same qualitative composition but differ by the relative amounts of each compound, depending on the analyzed macrogolglyceride.

As expected, the data analysis (descriptive statistics and multivariate analysis) of both the compositions, showed a 
higher presence of linoleic esters for LM (mainly expressed in MEPEGs, DGs, DEPEGs and TGs compounds), and a higher presence of oleic esters for OM (mainly expressed in MEPEGs, DGs, DEPEGs and TG). In addition, for LM, a higher presence of TG $(18: 2 / 18: 2 / 18: 1),(18: 2 / 18: 2 / 16 / 0)$, TG (18:1/16:0/18:2) and TG (18:2/16:0/16:0) is highlighted and for OM, TG (18:1/18:2/18:1), TG (18:1/18:0/18:1) and (18:1/ 16:0/18:1).

The European Pharmacopoeia monographs for the quality control of these ingredients (OM and LM) propose to access the overall fatty acid profile after hydrolysis of all the esters. The purpose of this global approach was to characterize the pharmaceutical raw material through its main fatty acid i.e. oleic acid (C18:1) for OM and linoleic acid (C18:2) for LM. Nevertheless, it remains very interesting to have a more detailed molecular approach of OM and LM for a best understanding of their behavior during the manufacturing process of some dosage forms (such as nanocarriers). Indeed, their differences in the molecular distribution of OM and LM could lead to various functionality-related characteristics of these ingredients.

\section{Supplementary Material}

Supplementary data 1: RT, ECN and $\mathrm{m} / \mathrm{z}$ values of protonated molecular ion and main fragment ions of MGs and MPEGEs for LM and OM.

Supplementary data 2: RT, ECN and $\mathrm{m} / \mathrm{z}$ values of protonated molecular ion and main fragment ions of DGs and DPEGEs for LM and OM.

Supplementary data 3: $\mathrm{RT}, \mathrm{ECN}$ and $\mathrm{m} / \mathrm{z}$ values of protonated molecular ion and main fragment ions of TGs for LM and OM.

Supplementary data 4: Majority ions $(\mathrm{m} / \mathrm{z})$ of some constituents of LM and OM.

The Supplementary Material is available at http://www.ocljournal.org/10.1051/ocl/2020020/olm.

\section{Abbreviations}

$\begin{array}{ll}\text { LM } & \text { Linoleoyl macrogolglyceride } \\ \text { OM } & \text { Oleoyl macrogolglyceride } \\ \text { NARP } & \text { Non-aqueous reversed phase } \\ \text { HPLC } & \text { High-performance liquid chromatogra- } \\ & \text { phy } \\ \text { APPI } & \text { Atmospheric pressure photoionization } \\ \text { LTQ } & \text { Linear trap quadropole } \\ \text { MG } & \text { Monoglyceride } \\ \text { DG } & \text { Diglyceride } \\ \text { TG } & \text { Triglyceride } \\ \text { PEG } & \text { Polyethylene glycol } \\ \text { MPEGE } & \text { Mono-PEG esters } \\ \text { DPEGE } & \text { Di-PEG esters } \\ \text { ELSD } & \text { Evaporative light-scattering detector } \\ \text { CAD } & \text { Charged aerosol detector } \\ \text { APCI } & \text { Atmospheric pressure chemical ioniza- } \\ & \text { tion } \\ \text { ESI } & \text { Electrospray ionization }\end{array}$

MALDI

FTMS

TOF

CID

ISTD

TIC

RT

PCA

OPLS-DA

$\mathrm{CN}$

DB

ECN

EO

$\mathrm{R}$

$\mathrm{PC}$
Matrix-assisted laser desorption ionization

Fourier transform mass spectrometry

Time of flight mass spectrometry

Collision-induced dissociation

Chemical internal standard

Ion chromatogram

Retention time

Principal component analysis

Orthogonal partial least square-dis-

criminant analysis

Total carbon number

Double bonds

Equivalent carbon number

Ethylene oxide

Response factor

Principal component

\section{References}

Abdullah FZ, Ma'Amor A, Daud NA, et al. 2017. Selective synthesis of peg-monoester using cesium heteropoly acid as heterogeneous catalyst. Quím Nova 40: 506-512.

Castilho PC, do Costa MC, Rodrigues A, Branco PC, Costa M. 2004. Characterization of triacylglycerols in madeira laurel oil by HPLC-atmospheric pressure chemical ionization-MS. J Am Oil Chem Soc 81: 913-919.

Chen R, Yu X, Li L. 2002. Characterization of poly(ethylene glycol) esters using low energy collision-induced dissociation in electrospray ionization mass spectrometry. $J$ Am Soc Mass Spectrom 13: 888-897.

Fasciotti M, Pereira Netto AD. 2010. Optimization and application of methods of triacylglycerol evaluation for characterization of olive oil adulteration by soybean oil with HPLC-APCI-MS-MS. Talanta 81: 1116-1125.

Gómez-Ariza JL, Arias-Borrego A, García-Barrera T, Beltran R. 2006. Comparative study of electrospray and photospray ionization sources coupled to quadrupole time-of-flight mass spectrometer for olive oil authentication. Talanta 70: 859-869.

Holčapek M, Jandera P, Fischer J, Prokeš B. 1999. Analytical monitoring of the production of biodiesel by high-performance liquid chromatography with various detection methods. $J$ Chromatogr A 858: 13-31.

Holčapek M, Jandera P, Zderadička P, Hrubá L. 2003. Characterization of triacylglycerol and diacylglycerol composition of plant oils using high-performance liquid chromatography - Atmospheric pressure chemical ionization mass spectrometry. J Chromatogr A 1010: 195-215.

Holčapek M, Lísa M, Jandera P, Kabátová N. 2005. Quantitation of triacylglycerols in plant oils using HPLC with APCI-MS, evaporative light-scattering, and UV detection. J Sep Sci 28: 1315-1333.

Imbert L, Gaudin M, Libong D, et al. 2012. Comparison of electrospray ionization, atmospheric pressure chemical ionization and atmospheric pressure photoionization for a lipidomic analysis of Leishmania donovani. J Chromatogr A 1242: 75-83.

Jackson AT, Yates HT, MacDonald WA, et al. 1997. Time-lag focusing and cation attachment in the analysis of synthetic polymers by matrix-assisted laser desorption/ionization-time-offlight-mass spectrometry. J Am Soc Mass Spectrom 8: 132-139. 
Jakab A, Héberger K, Forgács E. 2002. Comparative analysis of different plant oils by high-performance liquid chromatographyAtmospheric pressure chemical ionization mass spectrometry. $J$ Chromatogr A 976: 255-263.

Labrafil $^{\circledR}$ M 2125 CS. Gattefossé. https://www.gattefosse.com/fr/ labrafil-m-2125-cs.

Labrafil $^{\circledR}$ M 1944 CS. Gattefossé. https://www.gattefosse.com/fr/ labrafil-m-1944-cs.

Lipid Maps ${ }^{\circledR}$ Lipidomics Gateway. https://www.lipidmaps.org/.

Lísa M, Holčapek M, Rezanka T, Kabátová N. 2007. Highperformance liquid chromatography-Atmospheric pressure chemical ionization mass spectrometry and gas chromatographyFlame ionization detection characterization of $\Delta 5$-polyenoic fatty acids in triacylglycerols from conifer seed oils. J Chromatogr A 1146: 67-77.

Lísa M, Netušilová K, Franěk L, et al. 2011. Characterization of fatty acid and triacylglycerol composition in animal fats using silverion and non-aqueous reversed-phase high-performance liquid chromatography/mass spectrometry and gas chromatography/ flame ionization detection. J Chromatogr A 1218: 7499-7510.

López-López A, Castellote-Bargalló AI, López-Sabater MC. 2001. Direct determination by high-performance liquid chromatography of sn-2 monopalmitin after enzymatic lipase hydrolysis. $J$ Chromatogr B Biomed Sci App 760: 97-105.

Maloumbi M-G, Heron S, Tchapla A. 2015. Analyse chromatographique des triglycerides pourquoi et comment? Partie II : Apport des chromatographies en phases liquide et supercritique. $J$ Soc Ouest-Afr Chim 22: 1-12.
Momchilova S, Tsuji K, Itabashi Y, Nikolova-Damyanova B, Kuksis A. 2004. Resolution of triacylglycerol positional isomers by reversed-phase high-performance liquid chromatography. J Sep Sci 27: 1033-1036.

Mottram HR, Evershed RP. 1996. Structure analysis of triacylglycerol positional isomers using atmospheric pressure chemical ionisation mass spectrometry. Tetrahedron Lett 37: 8593-8596.

MZmine 2. 2010. Download. http://mzmine.github.io/download.html.

Pastor SJ, Wilkins CL. 1998. Sustained off-resonance irradiation and collision-induced dissociation for structural analysis of polymers by MALDI-FTMS. Int J Mass Spectrom Ion Process 175: 81-92.

Rezanka T, Schreiberová O, Krulikovská T, Masák J, Sigler K. 2010. RP-HPLC/MS-APCI analysis of odd-chain TAGs from Rhodococcuserythropolis including some regioisomers. Chem Phys Lipids 163: 373-380.

Rezanka T, Pádrováb K, Siglera K. 2017. Regioisomeric and enantiomeric analysis of triacylglycerols. Anal Biochem 524: 3-12.

Salghi R, Armbruster W, Schwack W. 2014. Detection of argan oil adulteration with vegetable oils by high-performance liquid chromatography-Evaporative light scattering detection. Food Chem 153: 387-392.

Soumanou MM, Tchobo FP, Edorh AP, Accrombessi G. 2005. Valorisation des huiles végétales d'origine béninoise par alcoolyse enzymatique. Oil Corps Gras Lipides 12: 320-325.

Tamba Sompila AWG, Maloumbi MG, Bleton J, Tchapla A, Héron S. 2014. Identification des triacylglycérols en HPLC. Comment se passer du couplage HPLC-SM? Dans quel cas la chromatographie est-elle encore indispensable? OCL 21: A601.

Cite this article as: Kemel K, Libong D, Solgadi A, Tfaili S, Baillet-Guffroy A, Laugel C. 2020. Analysis of linoleoyl and oleoyl macrogolglycerides by high performance liquid chromatography coupled to the atmospheric pressure photoionization mass spectrometry. OCL 27: 26 . 